\title{
Viral Interaction with Molecular Chaperones: Role in Regulating Viral Infection
}

Allen Xiao, Jerry Wong, Honglin Luo ${ }^{1}$

The James Hogg iCAPTURE Centre for Cardiovascular and Pulmonary Research, Department of Pathology and Laboratory Medicine, University of British Columbia, Providence Heart + Lung Institute, St. Paul's Hospital, Vancouver, BC V6Z 1Y6, Canada

Running title: Molecular Chaperones in Viral Infection

${ }^{1}$ Correspondence to: Dr. Honglin Luo, The James Hogg iCAPTURE Centre for Cardiovascular and Pulmonary Research, University of British Columbia-St. Paul's Hospital, 1081 Burrard St., Vancouver, British Columbia, Canada V6Z 1Y6. Phone: 1- (604) 682-2344 ext. 62847. Fax: (604) 806-9274. E-mail: honglin.luo@hli.ubc.ca. 


\begin{abstract}
As essential effectors in protein quality control, molecular chaperones serve as the primary checkpoint to assist proper protein folding, and prevent misfolded proteins from denaturation and aggregation. In addition, chaperones can function to direct terminally-misfolded proteins to the proteolytic system for degradation. Viruses rely on host cell machineries for productive infection. Like for many other processes, various viruses have been shown to evolve mechanisms to utilize or subvert the host protein quality control machinery to support the completion of their life cycle. Furthermore, recent studies suggest that some viruses encode for their own chaperone-like proteins to enhance their infectivity. This review summarizes the current understanding of the interplay between molecular chaperones and viral proteins, highlights the chaperone activities of a number of viral proteins, and discusses potential anti-viral therapeutic strategies targeting the virus-chaperone interactions. (Words: 135)
\end{abstract}

Key Words: Chaperone, heat-shock protein, virus infection, protein folding, protein assembly 


\section{Introduction}

Molecular chaperones have traditionally been defined as a class of proteins that assist the non-covalent folding and assembly of other macromolecular structures, but are not part of these structures upon maturation. It is now evident that chaperone function is not limited to protein folding and assembly, but also include helping to prevent newly synthesized polypeptide chains and assembled subunits from aggregating into non-functional structures, transporting protein across membranes, and escorting terminally-misfolded proteins to the proteolytic system for degradation 55,78 . The general function of the intracellular molecular chaperones has been suggested mainly to involve housekeeping and cytoprotection against various environmental stresses. Studies indicate that many chapenones are induced during viral infection to either facilitate viral pathogenesis or to participate in a cellular response mechanism to alleviate the stress caused by infection $46,60,78$. In addition to using host chaperone proteins, some viruses encode for their own chaperone-like proteins to enhance their infectivity ${ }^{41,75,83}$. This review will outline the diversity and complexity of interactions between virus and chaperones, discuss the chaperone activities of a number of virus proteins, and summarize potential anti-viral therapeutic strategies targeting the virus-chaperone interactions.

\section{Molecular Chaperones and Their Biological Functions}

Molecular chaperones are a family of structurally unrelated proteins which participate in the regulation of multiple biological processes to maintain cellular homeostasis. As alluded to above, chaperones bind to misfolded or unfolded polypeptides to assist in their correct folding and assembly, regulate protein transport and translocation, and facilitate misfolded polypeptides for degradation by the ubiquitin-proteasome system (Figure 1) ${ }^{3,53,55}$. Dysregulation or 
mutations in molecular chaperones has been associated with a number of human diseases, including cardiovascular diseases, neurodegenerative diseases, and cancer ${ }^{58,61}$.

There are at least 20 different families of proteins with chaperone activity (refer to review ${ }^{28}$ for a detailed list). The best-characterized stress-induced chaperone families are the heat shock proteins (Hsps). Hsps are classified into at least six families on the basis of their molecular weight (e.g small Hsps, Hsp40 (DnaJ), Hsp60 (chaperonins), Hsp70, Hsp90, and Hsp100) ${ }^{39,58}$. These families of chaperones are highly conserved during evolution and are present in both cytosol and endoplasmic reticulum (ER) in almost all cell types. They recognize and interact with various non-native polypeptides via different mechanisms of action and promote their refolding to the native state ${ }^{39,58}$. This process is usually regulated by one or several cochaperones which function to modulate the activity of the chaperone. Most Hsps are constitutively synthesized but further induced in response to adverse environmental conditions such as high temperature, oxidative stress, and inflammation ${ }^{39,58}$.

The ER contains a large set of particular molecular chaperones helping the folding and assembly of newly synthesized proteins or misfolded proteins under ER stress. Malfunction of ER chaperones induced by ER stress leads to the unfolded protein response ${ }^{53,61}$. There are two major groups of ER chaperones: the glucose-regulated proteins (GRPs), and the calnexin/calreticulin chaperones ${ }^{53,61}$. The GRP78 (also known as BiP) and GRP94 are the ER homologues of Hsp70 and Hsp90, respectively. GRP78 assists in protein folding through specifically interacting with proteins containing hydrophobic residues in their misfolded/unfolded regions. While the function of GRP94 in ER protein quality control has not been fully elucidated, it was suggested that GRP94 may provide a platform for the assembly of the large ER chaperone complex under conditions of ER stress ${ }^{53,61}$. Calnexin is a type I ER 
membrane protein and calreticulin is a soluble ER lumen protein. These lectin-like ER chaperones recognize and interact with proteins that carry $\mathrm{N}$-linked glycans for subsequent protein folding and assembly ${ }^{53,61}$.

In addition to their intracellular localization and functions as discussed above, some molecular chaperones can also be present on the cell surface and/or secreted into the extracellular space under certain stress conditions. These membrane-associated or released chaperones have been reported to possess extracellular functions as important mediators of cell-cell signaling ${ }^{14}$. Among their multiple extracellular functions, their ability in eliciting both innate and adaptive immune responses makes them attractive targets for the development of vaccine ${ }^{8,69}$.

\section{Interplay between Viruses and Host Chaperones}

Virus infection often leads to increased production of cellular chaperones but it remains unclear whether this is a direct effect of virus infection or an indirect response to cellular stress induced by infection $46,60,78$. Viruses can regulate host chaperones at different levels, including transcription, translation, posttranslational modification, and cellular localization. Increased expression of heat shock proteins has been suggested to be biomarkers for some viral infections. As an example, Zhu et al. ${ }^{90}$ found that the elevated expression of the heat shock protein GRP94 significantly correlates with the disease progression of hepatitis B virus (HBV) infection and can therefore be used as a prognostic or diagnostic biomarker for HBV-induced diseases. Similarly, the expression of GRP78/BiP and Hsp90 was also reported to be upregulated in HBV-related hepatocellular carcinomas, suggesting that these chaperones may serve as important prognostic biomarkers for HBV-induced hepatic cancer ${ }^{49}$.

Accumulating evidence has indicated that chaperones have a wide array of functions during viral infection, and that each chaperone may play different roles during a particular viral 
infection. This review focuses on the functions of chaperones in viral host entry, viral genome nuclear import, viral replication, viral protein folding, virion assembly, host immunity regulation, and manipulating host apoptotic pathway. A summary of the interaction between viruses and host chaperones in regulating virus infection is illustrated in Figure 2.

\section{$\underline{\text { Cell Entry and Nuclear Import }}$}

Viruses are known to exploit chaperones for effective cellular entry by using them as part of the viral uncoating mechanism or as viral receptors. As an example, rotavirus entry requires the interaction with heat shock cognate protein 70 (Hsc70) at a postattachment step, functioning as part of a complex that brings about a conformational change of the viral capsid to facilitate its entry into the cytoplasm ${ }^{32,68,89}$. Similarly, simian virus 40 (SV40) was reported to utilize the host protein folding machinery for virus uncoating and entry into the host cells ${ }^{74}$. Additionally, chaperone proteins presented on cell surface can be utilized as viral receptors, such as Hsp90 and Hsp70 for dengue virus ${ }^{73}$, Hsp70 for Japanese encephalitis virus ${ }^{25}$, and GRP78 for coxsackievirus A9 ${ }^{84}$.

After successful host internalization, most DNA viruses and some RNA viruses, such as the retroviruses and the influenza viruses, require their genome to be imported into the nucleus, where replication takes place. Rainey-Barger et al. ${ }^{71}$ demonstrated that the ER chaperone protein ERp29 alters the conformation of polyomavirus capsid protein VP1 and exposes the internal viral protein VP2, which then perforates the ER membrane to allow the viral genome to reach the nucleus for replication. In addition, Hsc70 was also implicated to play a role in polyomavirus genome nuclear import through its association with viral capsid proteins ${ }^{23}$. 
During human immunodeficiency virus type 1 (HIV-1) infection, Hsp70 plays a similar role to that of the HIV-1 viral protein $\mathrm{R}$ (Vpr), stimulating an interaction between the viral preintegration complex and karyopherin- $\alpha$ to promote viral nuclear import ${ }^{1}$. Interestingly, Iordanskiy et al. ${ }^{35}$ argued for an antiviral role of $\mathrm{Hsp} 70$, where it only functions similarly as $\mathrm{Vpr}$ when expressed alone, but in the presence of $\mathrm{Vpr}$, it neutralizes $\mathrm{Vpr}$ function and inhibits its nuclear translocation, rendering it unable to assist the nuclear translocation of the viral preintegration complex.

\section{Viral Replication and Gene Expression}

The next steps following viral entry are the replication of the viral genome and the expression of viral proteins, which are also facilitated by host chaperons. Cyclophilins are molecular chaperones that promote protein folding through their isomerase activity ${ }^{2}$. It was reported that hepatitis $\mathrm{C}$ virus (HCV) non-structural protein 5B (NS5B), an RNA-dependent RNA polymerase essential for viral genome replication, associates with the enzymatic pocket of cyclophilin A, exploiting its isomerase or chaperone activity to enhance its maturation ${ }^{17}$. Similarly, Waxman et al. ${ }^{86}$ also identified Hsp90 chaperone as an essential factor for the maturation and activity of the $\mathrm{HCV}$ NS2/3 protease, which is necessary for viral replication. Other studies further elucidated the role of $\mathrm{Hsp} 90$ in HCV RNA replication by forming a chaperone complex with NS5A, a component of viral replicase, and FKBP8, a member of the FK506-binding protein family ${ }^{62}$.

Hsp90 has been demonstrated to be involved in the reverse transcription of HBV genome. It was suggested that Hsp90 helps bridge the two separate reverse transcriptase domains of HBV together to enable the formation of a ribonucleoprotein complex with the HBV RNA ${ }^{34}$. As for 
the replication of HBV RNA genome, the glucose-regulated chaperone protein GRP94 is found to be a critical regulator in the stabilization and activation of HBV RNA polymerase, allowing its preferential binding to the HBV $\varepsilon$ RNA ${ }^{38}$. Furthermore, the molecular chaperonin Hsp60 is shown to participate in the activation of $\mathrm{HBV}$ polymerase prior to its encapsidation into the core particle, which is required for initiating HBV replication in newly infected cells ${ }^{65,66,76}$.

During influenza virus infection, Hsp90 interacts with the viral RNA-dependent RNA polymerase, playing a role in the assembly and nuclear transport of viral RNA polymerase subunits en route to the formation of a mature polymerase complex ${ }^{57,59}$. Additionally, heat shock proteins Hsp70 and Hsp40 enhance binding of the papillomavirus replication initiator E1 helicase to the origin of DNA replication, thus indirectly enhancing viral replication ${ }^{50}$. As another example, flock house virus infection induces the expression of Hsp90, which participates in viral RNA replication as part of cellular pathways used by the virus for assembling RNA replication complexes on intracellular membranes ${ }^{37}$.

Chaperones can also be involved in regulating viral gene expression. For instance, it has been shown that HIV-1 protein Nef indirectly facilitates viral gene expression by inducing the expression of Hsp40 and interacting with Hsp40 to promote its nuclear translocation and association with the cyclin-dependent kinase 9 transcription complex that regulates long terminal repeat-mediated gene expression ${ }^{42}$.

\section{Folding/Assembly of Viral Protein}

True to their definition, a major function of chaperones is to assist the folding and assembly of viral proteins and virions into functional conformations. In particular, the 
dependence of viruses on the ER for folding/assembly renders ER chaperones the major facilitators of proper viral morphogenesis, but other chaperones are often recruited as well.

An important step in viral morphogenesis of enveloped viruses is the formation of the viral envelope. In the case of $\mathrm{HCV}$ infection, the ER chaperone calnexin is involved in the productive assembly of the envelope glycoproteins E1 and E2 into a heterodimer, and that it is during this dimerization process that the proper folding of the glycoproteins is achieved ${ }^{20,26,27}$. Other ER chaperones, GRP78/BiP and calreticulin, were reported to interact with misfolded aggregates containing HCV viral glycoproteins, likely involved in their repair ${ }^{27}$.

HBV infection leads to the large L envelope protein acquiring a dual membrane topology in order to mediate hepatocyte receptor binding and envelopment of cytosolic nucleocapsids ${ }^{70}$. The preS domain of L protein initially remains in the cytosol as the S domain is cotranslationally inserted into the ER membrane, and subsequently, the preS domain is translocated to the lumenal space $^{70}$. Studies revealed that Hsc70 and Hsp40 associate with L protein, likely to assist the initial suppression of the cotranslational translocation of the preS domain, and also identified the ER chaperone GRP78/BiP to be responsible for assisting the subsequent posttranslational translocation of the preS domain ${ }^{4,19,43,52}$. HBV M protein also requires the chaperone activity of calnexin, which selectively binds to the $\mathrm{N}$-glycan specific to viral $\mathrm{M}$ protein to facilitate proper folding and trafficking ${ }^{70}$.

During polyomavirus infection, it was demonstrated that Hsc70 binds coat protein VP1 and regulates the quality and location of viral capsid assembly ${ }^{21}$. Final assembly of viruses such as rotavirus and cytomegalovirus, occurs in the ER. It has been demonstrated that the ER chaperones GRP78/BiP, calnexin, and calreticulin are involved in the maturation of the oligosaccharide chains of the non-structural viral protein NSP4, oxidative folding of VP7, and 
formation of disulfide bonds of VP7. All of these processes are important for correct assembly of viral particles ${ }^{54}$. A recent study by Buchkovich et al. ${ }^{11}$ found that protein levels of the ER chaperone GRP78/BiP are tightly regulated during cytomegalovirus infection, and showed that this regulation enhances cytoplasmic virion assembly and egress.

The well-characterized ability to facilitate glycoprotein folding renders ER chaperones essential to some viruses. For influenza virus, early maturation steps of its glycoprotein hemagglutinin involve glycosylation by N-linked glycans, leading to the binding of ER chaperones calnexin and calreticulin that facilitate productive folding of this viral glycoprotein ${ }^{24}$. During measles virus infection, it was revealed that nascent viral fusion glycoprotein binds to calnexin as a vital step in achieving its functional conformation, and that ER chaperones may withhold the migration of viral glycoproteins to the cell surface, possibly to repair misfolding ${ }^{9}$. Immunoprecipitation studies also showed that GRP78/BiP binds maximally to early folding intermediates of vesicular stomatitis virus glycoprotein, whereas calnexin binds subsequently to more folded molecules ${ }^{33}$. This binding sequence is necessary for efficient folding of vesicular stomatitis virus glycoprotein and for the retention of its partially folded forms ${ }^{33}$. Similarly, the unfolded glycoprotein of rabies virus is associated first with GRP78/BiP and subsequently with calnexin, perhaps as part of a folding mechanism ${ }^{29}$.

Other chaperone involvement in virus folding/assembly has also been described. It was shown that Hsp90 binds in a p53-independent and ATP-dependent manner to immature conformations of the SV40 large tumour antigen (TAg), possibly to assist its formation into a functional structure ${ }^{56}$. Recently, Hsp90 was also suggested to be involved in the process of viral capsid protein folding and assembly of various picornavirus, including poliovirus, rhinovirus, and coxsackievirus ${ }^{30}$. A virion morphology study revealed that the chaperone cyclophilin A 
modulates HIV-1 infectivity through its interactions with viral gag structural proteins ${ }^{77}$. In the presence of cyclosporine A, a cyclophilin A inhibitor, viral particles display immature virion morphology, indicating that cyclophilin A plays an important role in the maturation of HIV-1 particles that is essential for virion assembly ${ }^{77}$.

\section{Apoptosis Regulation and Host Immunity}

Various viruses have evolved different mechanisms to modulate the apoptotic pathway to benefit their growth in host cells. Chaperones can be utilized by viruses to participate in regulating cell apoptosis. It was demonstrated that HIV-1 infection induces overexpression of Hsp70, which interacts with Hsp27 and Vpr to protect cells from virus-induced G2 arrest and apoptosis ${ }^{12,35}$. As another example, the Epstein-Barr virus nuclear oncoprotein EBNA3A induces transcriptional upregulation and nuclear translocation of $\mathrm{Hsp} 70$ and formation of an active Hsp70 chaperone complex, which helps ensure protein stability and contributes to the immortalization of $\mathrm{B}$ cells as part of an anti-apoptotic effect ${ }^{88}$. In addition, the E2 envelope protein of HCV has been shown to block virus-induced apoptosis by inducing the overexpression of the glucose-regulated chaperone proteins GRP94 ${ }^{44,48}$. Chaperones have also been reported to facilitate apoptosis. Tanaka et al. ${ }^{81}$ reported that during HBV infection, HBx interaction with chaperone Hsp60 brings about their colocalization in the mitochondria, where Hsp60 promotes HBx-induced apoptosis.

As discussed previously, some extracellular chaperones also have immunological properties $^{8,69}$. They activate dendritic cells and natural killer cells, promote antigen presentation, and stimulate adaptive T-lymphocyte and humoral immune responses against antigenic peptides. During virus infection, molecular chaperones are also involved in the regulation of virus-induced 
host immune response. For example, during Epstein-Barr virus infection, Hsp90 was identified to play an important role in promoting $\gamma \delta \mathrm{T}$ proliferation in B cells as part of the host immune response against virus infection ${ }^{40}$.

\section{The Chaperone-Like Activities of Virus Proteins}

In addition to utilizing host chaperones, some viral proteins also exhibit chaperone-like activity that facilitates their infection. The virus-encoded proteins with chaperone function are summarized and shown in Table $\mathbf{1 .}$

A well-studied viral-encoded chaperone is the SV40 TAg. This multifunctional protein has functional J domains of Hsp40, which is required for the recruitment of host Hsp70 to complete the SV40 virion assembly ${ }^{75}$. The chaperone-like functions of TAg is also found to facilitate viral replication, transcriptional regulation, and cell cycle alteration ${ }^{79}$.

In addition, the R1 subunit of HSV ribonucleotide reductase, which protects cells against apoptosis, has chaperone-like activity similar to Hsp2 ${ }^{15}$. This chaperone activity has been proposed to have an anti-apoptotic effect that contributes to the successful infection of the virus 15. HSV type 2 was also reported to encode for a homologue (ICP10PK) to small Hsp11 to modulate virus-induced apoptosis via activation of the ERK signaling pathway, stabilization of Bcl-2 and upregulation of other apoptosis regulators such as Hsp70 and Hsp27 ${ }^{31}$. The rotavirus non-structural glycoprotein NSP4 was also shown to act as an ER chaperone to regulate the folding of structural protein VP4 and also facilitate the transport systems through the ER membrane during virion assembly ${ }^{80}$. During African swine fever virus infection, virus-encoded capsid-associated protein 80 functions as a chaperone assisting proper folding of the major capsid protein $\mathrm{p} 73^{22}$. 
Virus can also encode for their own nucleic acid chaperones to assist proper viral RNA/DNA folding for efficient viral replication. The most extensively studied example is the ability of HIV-1 to encode for nucleocapsid (NC) protein to chaperone viral DNA replication ${ }^{82}$. Specifically, the HIV-1 NC is involved in the two obligatory strand transfers required during reverse transcription to convert its genomic RNA into proviral DNA ${ }^{72,82}$. Furthermore, HIV-1 encoded small nuclear transcriptional activator Tat has also been demonstrated to have nucleic acid-chaperoning activities. The Tat protein is required for HIV-1 replication due to its regulation of proviral DNA transcription to generate full-length viral mRNA ${ }^{41}$. In this paper, we have discussed only a few examples of nucleic acid chaperones in viral replication as this topic has been extensively reviewed ${ }^{91}$.

\section{Molecular Chaperones in Antiviral Therapy}

In light of the wide array of interactions between viruses and chaperones, putative therapeutic strategies against viral infection involving chaperones have emerged. Chaperone inhibitors have been explored in the development of antiviral strategies. For examples, Hsp90 inhibitors have been suggested as therapeutic agents for picornavirus infection ${ }^{30}$. One of the best-known chaperone inhibitor is geldanamycin (GA), which specifically competes for ATP binding with Hsp90 to block its ATPase activity and thus prevent client protein cycling and maturation ${ }^{60}$. It was shown that pharmacological inhibition of Hsp90 by GA impairs the replication of poliovirus, rhinovirus, and coxsackievirus in cells, and in vivo administration of GA significantly decreases virus load in poliovirus-infected mice without the emergence of drug-

resistant escape mutants ${ }^{30}$. The mechanism of action of GA on picornaviral infection is likely the inhibition of viral capsid protein folding and assembly ${ }^{30}$. Studies also showed that GA, or its 
derivative 17-allylamino-17-demethoxygeldanamycin (17-AAG), delays the growth of influenza virus by inhibiting nuclear import and assembly of viral RNA polymerase complex ${ }^{16}$, and suppresses the replication of $\mathrm{HCV}$ through destabilizing non-structural protein NS3 ${ }^{85}$. In addition, GA inhibits HSV-1 replication by promoting aberrant folding, mislocalization, and proteasomal degradation of the viral polymerase ${ }^{13,47}$. In the case of HBV infection, a study by Liu et al. ${ }^{51}$ established the multichaperone machine formed by Hsp90 and Hsp70/Hsp60 as a potential target for development of antiviral therapeutic strategies. Some host signaling molecules including phosphatidylinositol 3-kinase (PI3K) and AKT proteins are also identified to be the client proteins of the Hsp90. As for Epstein-Barr virus, a therapeutic strategy was proposed to target the PI3K/Akt pathway ${ }^{36}$. It was speculated that Hsp90 inhibitors can disrupt the PI3K/Akt pathway, and can potentially be used for achieving control of the natural killer/Tcell lymphoma associated with Epstein-Barr virus infection ${ }^{36}$. GA was also reported to block cytomegalovirus replication via disruption of the PI3K/Akt signaling pathway ${ }^{7}$. Thus, the dependence of viral infection on Hsp90-dependent client proteins makes GA and other Hsp90 inhibitors promising anti-viral compounds.

Other chaperone inhibitors also have therapeutic potential. Chen et al. ${ }^{18}$ identified novel non-peptidic inhibitors against chaperone cyclophilin A as potential anti-HIV compounds. Cyclophilin inhibitors such as cyclosporine A, Debio 025, NIM811 and SCY-635 are also potential anti-HCV compounds due to their ability to inhibit HCV replication ${ }^{17}$. Recently, Wright et al. ${ }^{87}$ also identified the small molecular compound MAL2-11B as a novel inhibitor for the chaperone activity of the SV40 TAg, thus indicating a novel approach to combating polyomavirus-mediated disease. 
As alluded to earlier, the ability of heat shock proteins to interact with viral proteins, together with their inherent adjuvant and immunogenic properties, render them as attractive candidates for the development of anti-viral vaccines ${ }^{10}$. Lehner et al. ${ }^{45}$ suggested a novel strategy of immunization with Hsp70 linked to antigen to generate both cognate and innate immunity to prevent binding and transmission of simian immunodeficiency virus. In particular, Babaahmady et al. ${ }^{5}$ showed that microbial Hsp70 exerts a dose-dependent inhibitory effect on HIV-1 infection of CD4+ T cells, and proposed a combined treatment with Hsp70 and antibody to the CCR5 strain of CD4+ T cells as a potential immunization strategy against HIV-1 infection. They also proposed a vaccination approach of utilizing a Hsp70-containing trimolecular complex of human antisera to elicit broadly neutralizing antibody activity to HIV $-1{ }^{6}$. Similarly, Peng et al.

${ }^{67}$ identified the mycobacterium tuberculosis Hsp70 as a potential adjuvant for the development of prophylactic and therapeutic vaccines for chronic HBV infection. Hsp70 was also proposed to be useful in the design of vaccines for $\mathrm{HSV}^{63,64}$.

Table 2 summarizes the therapeutic strategies targeting molecular chaperones for the treatment of virus infection.

\section{Conclusion}

It is evident that chaperones are elicited during a wide array of viral infections to play important roles at various stages of the viral life cycle to either enhance or inhibit pathogenesis. This review of the roles played by heat shock proteins and other chaperones is by no means comprehensive, but simply a broad sketch of studies done in this expanding area. As evidenced by the numerous potential therapeutic modalities against virus infection based on our 
understanding of chaperone involvement, further understanding of this particular aspect of virus infection will have significant therapeutic potential. 


\section{Acknowledgements}

This manuscript was supported by grants from the Heart and Stroke Foundation of British Columbia and Yukon (HL) and the Canadian Institutes of Health Research (HL). JW is a recipient of a Doctoral Traineeship from the CIHR. 


\section{References:}

1. Agostini I, Popov S, Li J, Dubrovsky L, Hao T, Bukrinsky M (2000) Heat-shock protein 70 can replace viral protein R of HIV-1 during nuclear import of the viral preintegration complex. Exp Cell Res 259: 398-403

2. Andreeva L, Heads R, Green CJ (1999) Cyclophilins and their possible role in the stress response. Int J Exp Pathol 80: 305-315

3. Arndt V, Rogon C, Hohfeld J (2007) To be, or not to be--molecular chaperones in protein degradation. Cell Mol Life Sci 64: 2525-2541

4. Awe K, Lambert C, Prange R (2008) Mammalian BiP controls posttranslational ER translocation of the hepatitis B virus large envelope protein. FEBS Lett 582: 3179-3184

5. Babaahmady K, Oehlmann W, Singh M, Lehner T (2007) Inhibition of human immunodeficiency virus type 1 infection of human CD4+ T cells by microbial HSP70 and the peptide epitope 407-426. J Virol 81: 3354-3360

6. Babaahmady K, Bergmeier LA, Lehner T (2008) Combining human antisera to human leukocyte antigens, HIVgp120 and $70 \mathrm{kDa}$ heat shock protein results in broadly neutralizing activity to HIV-1. Aids 22: 1267-1276

7. Basha W, Kitagawa R, Uhara M, Imazu H, Uechi K, Tanaka J (2005) Geldanamycin, a potent and specific inhibitor of Hsp90, inhibits gene expression and replication of human cytomegalovirus. Antivir Chem Chemother 16: 135-146

8. Beachy SH, Kisailus AJ, Repasky EA, Subjeck JR, Wang XY, Kazim AL (2007) Engineering secretable forms of chaperones for immune modulation and vaccine development. Methods 43: 184-193

9. Bolt G (2001) The measles virus (MV) glycoproteins interact with cellular chaperones in the endoplasmic reticulum and MV infection upregulates chaperone expression. Arch Virol 146: 2055-2068

10. Brenner BG, Wainberg MA (1999) Heat shock protein-based therapeutic strategies against human immunodeficiency virus type 1 infection. Infect Dis Obstet Gynecol 7: 8090

11. Buchkovich NJ, Maguire TG, Yu Y, Paton AW, Paton JC, Alwine JC (2008) Human cytomegalovirus specifically controls the levels of the endoplasmic reticulum chaperone BiP/GRP78, which is required for virion assembly. J Virol 82: 31-39

12. Bukrinsky M, Zhao Y (2004) Heat-shock proteins reverse the G2 arrest caused by HIV-1 viral protein R. DNA Cell Biol 23: 223-225

13. Burch AD, Weller SK (2005) Herpes simplex virus type 1 DNA polymerase requires the mammalian chaperone hsp90 for proper localization to the nucleus. J Virol 79: 1074010749

14. Calderwood SK, Mambula SS, Gray PJ, Jr., Theriault JR (2007) Extracellular heat shock proteins in cell signaling. FEBS Lett 581: 3689-3694

15. Chabaud S, Lambert H, Sasseville AM, Lavoie H, Guilbault C, Massie B, Landry J, Langelier Y (2003) The R1 subunit of herpes simplex virus ribonucleotide reductase has chaperone-like activity similar to Hsp27. FEBS Lett 545: 213-218

16. Chase G, Deng T, Fodor E, Leung BW, Mayer D, Schwemmle M, Brownlee G (2008) Hsp90 inhibitors reduce influenza virus replication in cell culture. Virology 377: 431-439 
17. Chatterji U, Bobardt M, Selvarajah S, Yang F, Tang H, Sakamoto N, Vuagniaux G, Parkinson T, Gallay P (2009) The isomerase active site of cyclophilin A is critical for hepatitis C virus replication. J Biol Chem 284: 16998-17005

18. Chen S, Zhao X, Tan J, Lu H, Qi Z, Huang Q, Zeng X, Zhang M, Jiang S, Jiang H, Yu L (2007) Structure-based identification of small molecule compounds targeting cell cyclophilin A with anti-HIV-1 activity. Eur J Pharmacol 565: 54-59

19. Cho DY, Yang GH, Ryu CJ, Hong HJ (2003) Molecular chaperone GRP78/BiP interacts with the large surface protein of hepatitis B virus in vitro and in vivo. J Virol 77: 27842788

20. Choukhi A, Ung S, Wychowski C, Dubuisson J (1998) Involvement of endoplasmic reticulum chaperones in the folding of hepatitis $\mathrm{C}$ virus glycoproteins. J Virol 72: 38513858

21. Chromy LR, Pipas JM, Garcea RL (2003) Chaperone-mediated in vitro assembly of Polyomavirus capsids. Proc Natl Acad Sci U S A 100: 10477-10482

22. Cobbold C, Windsor M, Wileman T (2001) A virally encoded chaperone specialized for folding of the major capsid protein of African swine fever virus. J Virol 75: 7221-7229

23. Cripe TP, Delos SE, Estes PA, Garcea RL (1995) In vivo and in vitro association of hsc70 with polyomavirus capsid proteins. J Virol 69: 7807-7813

24. Daniels R, Kurowski B, Johnson AE, Hebert DN (2003) N-linked glycans direct the cotranslational folding pathway of influenza hemagglutinin. Mol Cell 11: 79-90

25. Das S, Laxminarayana SV, Chandra N, Ravi V, Desai A (2009) Heat shock protein 70 on Neuro2a cells is a putative receptor for Japanese encephalitis virus. Virology 385: 47-57

26. Dubuisson J, Rice CM (1996) Hepatitis C virus glycoprotein folding: disulfide bond formation and association with calnexin. J Virol 70: 778-786

27. Dubuisson $\mathrm{J}$ (1998) [The role of chaperone proteins in the assembly of envelope proteins of hepatitis C virus]. Bull Mem Acad R Med Belg 153: 343-349; discussion 350-341

28. Ellis J (2005) Chaperone Function: The Orthodox View. In: Henderson B and Pockley G (ed) Molecular chaperons and cell signaling, Cambridge, pp 3-21. dol: $10.2277 / 0521836549$

29. Gaudin Y (1997) Folding of rabies virus glycoprotein: epitope acquisition and interaction with endoplasmic reticulum chaperones. J Virol 71: 3742-3750

30. Geller R, Vignuzzi M, Andino R, Frydman J (2007) Evolutionary constraints on chaperone-mediated folding provide an antiviral approach refractory to development of drug resistance. Genes Dev 21: 195-205

31. Gober MD, Wales SQ, Aurelian L (2005) Herpes simplex virus type 2 encodes a heat shock protein homologue with apoptosis regulatory functions. Front Biosci 10: 27882803

32. Guerrero CA, Bouyssounade D, Zarate S, Isa P, Lopez T, Espinosa R, Romero P, Mendez E, Lopez S, Arias CF (2002) Heat shock cognate protein 70 is involved in rotavirus cell entry. J Virol 76: 4096-4102

33. Hammond C, Helenius A (1994) Folding of VSV G protein: sequential interaction with $\mathrm{BiP}$ and calnexin. Science 266: 456-458

34. $\mathrm{Hu}$ J, Anselmo D (2000) In vitro reconstitution of a functional duck hepatitis B virus reverse transcriptase: posttranslational activation by Hsp90. J Virol 74: 11447-11455 
35. Iordanskiy S, Zhao Y, Dubrovsky L, Iordanskaya T, Chen M, Liang D, Bukrinsky M (2004) Heat shock protein 70 protects cells from cell cycle arrest and apoptosis induced by human immunodeficiency virus type 1 viral protein R. J Virol 78: 9697-9704

36. Jeon YK, Park CH, Kim KY, Li YC, Kim J, Kim YA, Paik JH, Park BK, Kim CW, Kim YN (2007) The heat-shock protein 90 inhibitor, geldanamycin, induces apoptotic cell death in Epstein-Barr virus-positive NK/T-cell lymphoma by Akt down-regulation. J Pathol 213: 170-179

37. Kampmueller KM, Miller DJ (2005) The cellular chaperone heat shock protein 90 facilitates Flock House virus RNA replication in Drosophila cells. J Virol 79: 6827-6837

38. Kim SS, Shin HJ, Cho YH, Rho HM (2000) Expression of stable hepatitis B viral polymerase associated with GRP94 in E. coli. Arch Virol 145: 1305-1320

39. Kosmaoglou M, Schwarz N, Bett JS, Cheetham ME (2008) Molecular chaperones and photoreceptor function. Prog Retin Eye Res 27: 434-449

40. Kotsiopriftis M, Tanner JE, Alfieri C (2005) Heat shock protein 90 expression in EpsteinBarr virus-infected B cells promotes gammadelta T-cell proliferation in vitro. J Virol 79: 7255-7261

41. Kuciak M, Gabus C, Ivanyi-Nagy R, Semrad K, Storchak R, Chaloin O, Muller S, Mely Y, Darlix JL (2008) The HIV-1 transcriptional activator Tat has potent nucleic acid chaperoning activities in vitro. Nucleic Acids Res 36: 3389-3400

42. Kumar M, Mitra D (2005) Heat shock protein 40 is necessary for human immunodeficiency virus-1 Nef-mediated enhancement of viral gene expression and replication. J Biol Chem 280: 40041-40050

43. Lambert C, Prange R (2003) Chaperone action in the posttranslational topological reorientation of the hepatitis $\mathrm{B}$ virus large envelope protein: Implications for translocational regulation. Proc Natl Acad Sci U S A 100: 5199-5204

44. Lee SH, Song R, Lee MN, Kim CS, Lee H, Kong YY, Kim H, Jang SK (2008) A molecular chaperone glucose-regulated protein 94 blocks apoptosis induced by virus infection. Hepatology 47: 854-866

45. Lehner T, Mitchell E, Bergmeier L, Singh M, Spallek R, Cranage M, Hall G, Dennis M, Villinger F, Wang Y (2000) The role of gammadelta $\mathrm{T}$ cells in generating antiviral factors and beta-chemokines in protection against mucosal simian immunodeficiency virus infection. Eur J Immunol 30: 2245-2256

46. Lewthwaite J, Skinner A, Henderson B (1998) Are molecular chaperones microbial virulence factors? Trends Microbiol 6: 426-428

47. Li YH, Tao PZ, Liu YZ, Jiang JD (2004) Geldanamycin, a ligand of heat shock protein 90, inhibits the replication of herpes simplex virus type 1 in vitro. Antimicrob Agents Chemother 48: 867-872

48. Liberman E, Fong YL, Selby MJ, Choo QL, Cousens L, Houghton M, Yen TS (1999) Activation of the grp78 and grp94 promoters by hepatitis $\mathrm{C}$ virus E2 envelope protein. $\mathrm{J}$ Virol 73: 3718-3722

49. Lim SO, Park SG, Yoo JH, Park YM, Kim HJ, Jang KT, Cho JW, Yoo BC, Jung GH, Park CK (2005) Expression of heat shock proteins (HSP27, HSP60, HSP70, HSP90, GRP78, GRP94) in hepatitis B virus-related hepatocellular carcinomas and dysplastic nodules. World J Gastroenterol 11: 2072-2079

50. Liu JS, Kuo SR, Makhov AM, Cyr DM, Griffith JD, Broker TR, Chow LT (1998) Human Hsp70 and Hsp40 chaperone proteins facilitate human papillomavirus-11 E1 
protein binding to the origin and stimulate cell-free DNA replication. J Biol Chem 273: 30704-30712

51. Liu K, Qian L, Wang J, Li W, Deng X, Chen X, Sun W, Wei H, Qian X, Jiang Y, He F (2009) Two-dimensional blue native/SDS-PAGE analysis reveals heat shock protein chaperone machinery involved in hepatitis B virus production in HepG2.2.15 cells. Mol Cell Proteomics 8: 495-505

52. Loffler-Mary H, Werr M, Prange R (1997) Sequence-specific repression of cotranslational translocation of the hepatitis B virus envelope proteins coincides with binding of heat shock protein Hsc70. Virology 235: 144-152

53. Ma Y, Hendershot LM (2004) ER chaperone functions during normal and stress conditions. J Chem Neuroanat 28: 51-65

54. Maruri-Avidal L, Lopez S, Arias CF (2008) Endoplasmic reticulum chaperones are involved in the morphogenesis of rotavirus infectious particles. J Virol 82: 5368-5380

55. McClellan AJ, Tam S, Kaganovich D, Frydman J (2005) Protein quality control: chaperones culling corrupt conformations. Nat Cell Biol 7: 736-741

56. Miyata Y, Yahara I (2000) p53-independent association between SV40 large T antigen and the major cytosolic heat shock protein, HSP90. Oncogene 19: 1477-1484

57. Momose F, Naito T, Yano K, Sugimoto S, Morikawa Y, Nagata K (2002) Identification of Hsp90 as a stimulatory host factor involved in influenza virus RNA synthesis. J Biol Chem 277: 45306-45314

58. Muchowski PJ, Wacker JL (2005) Modulation of neurodegeneration by molecular chaperones. Nat Rev Neurosci 6: 11-22

59. Naito T, Momose F, Kawaguchi A, Nagata K (2007) Involvement of Hsp90 in assembly and nuclear import of influenza virus RNA polymerase subunits. J Virol 81: 1339-1349

60. Neckers L, Tatu U (2008) Molecular chaperones in pathogen virulence: emerging new targets for therapy. Cell Host Microbe 4: 519-527

61. Ni M, Lee AS (2007) ER chaperones in mammalian development and human diseases. FEBS Lett 581: 3641-3651

62. Okamoto T, Nishimura Y, Ichimura T, Suzuki K, Miyamura T, Suzuki T, Moriishi K, Matsuura Y (2006) Hepatitis C virus RNA replication is regulated by FKBP8 and Hsp90. EMBO J 25: 5015-5025

63. Pack CD, Kumaraguru U, Suvas S, Rouse BT (2005) Heat-shock protein 70 acts as an effective adjuvant in neonatal mice and confers protection against challenge with herpes simplex virus. Vaccine 23: 3526-3534

64. Pack CD, Gierynska M, Rouse BT (2008) An intranasal heat shock protein based vaccination strategy confers protection against mucosal challenge with herpes simplex virus. Hum Vaccin 4: 360-364

65. Park SG, Jung G (2001) Human hepatitis B virus polymerase interacts with the molecular chaperonin Hsp60. J Virol 75: 6962-6968

66. Park SG, Lee SM, Jung G (2003) Antisense oligodeoxynucleotides targeted against molecular chaperonin Hsp60 block human hepatitis B virus replication. J Biol Chem 278: 39851-39857

67. Peng M, Chen M, Ling N, Xu H, Qing Y, Ren H (2006) Novel vaccines for the treatment of chronic HBV infection based on mycobacterial heat shock protein 70 . Vaccine 24: 887-896 
68. Perez-Vargas J, Romero P, Lopez S, Arias CF (2006) The peptide-binding and ATPase domains of recombinant hsc70 are required to interact with rotavirus and reduce its infectivity. J Virol 80: 3322-3331

69. Pockley AG, Muthana M, Calderwood SK (2008) The dual immunoregulatory roles of stress proteins. Trends Biochem Sci 33: 71-79

70. Prange R, Werr M, Loffler-Mary H (1999) Chaperones involved in hepatitis B virus morphogenesis. Biol Chem 380: 305-314

71. Rainey-Barger EK, Magnuson B, Tsai B (2007) A chaperone-activated nonenveloped virus perforates the physiologically relevant endoplasmic reticulum membrane. J Virol 81: 12996-13004

72. Ramalanjaona N, de Rocquigny H, Millet A, Ficheux D, Darlix JL, Mely Y (2007) Investigating the mechanism of the nucleocapsid protein chaperoning of the second strand transfer during HIV-1 DNA synthesis. J Mol Biol 374: 1041-1053

73. Reyes-Del Valle J, Chavez-Salinas S, Medina F, Del Angel RM (2005) Heat shock protein 90 and heat shock protein 70 are components of dengue virus receptor complex in human cells. J Virol 79: 4557-4567

74. Schelhaas M, Malmstrom J, Pelkmans L, Haugstetter J, Ellgaard L, Grunewald K, Helenius A (2007) Simian Virus 40 depends on ER protein folding and quality control factors for entry into host cells. Cell 131: 516-529

75. Spence SL, Pipas JM (1994) SV40 large T antigen functions at two distinct steps in virion assembly. Virology 204: 200-209

76. Stahl M, Retzlaff M, Nassal M, Beck J (2007) Chaperone activation of the hepadnaviral reverse transcriptase for template RNA binding is established by the Hsp70 and stimulated by the Hsp90 system. Nucleic Acids Res 35: 6124-6136

77. Streblow DN, Kitabwalla M, Malkovsky M, Pauza CD (1998) Cyclophilin a modulates processing of human immunodeficiency virus type 1 p55Gag: mechanism for antiviral effects of cyclosporin A. Virology 245: 197-202

78. Sullivan CS, Pipas JM (2001) The virus-chaperone connection. Virology 287: 1-8

79. Sullivan CS, Pipas JM (2002) T antigens of simian virus 40: molecular chaperones for viral replication and tumorigenesis. Microbiol Mol Biol Rev 66: 179-202

80. Suzuki H (1996) A hypothesis about the mechanism of assembly of double-shelled rotavirus particles. Arch Virol Suppl 12: 79-85

81. Tanaka Y, Kanai F, Kawakami T, Tateishi K, Ijichi H, Kawabe T, Arakawa Y, Nishimura T, Shirakata Y, Koike K, Omata M (2004) Interaction of the hepatitis B virus $\mathrm{X}$ protein $(\mathrm{HBx})$ with heat shock protein 60 enhances $\mathrm{HBx}$-mediated apoptosis. Biochem Biophys Res Commun 318: 461-469

82. Thomas JA, Bosche WJ, Shatzer TL, Johnson DG, Gorelick RJ (2008) Mutations in human immunodeficiency virus type 1 nucleocapsid protein zinc fingers cause premature reverse transcription. J Virol 82: 9318-9328

83. Thomas JA, Gorelick RJ (2008) Nucleocapsid protein function in early infection processes. Virus Res 134: 39-63

84. Triantafilou K, Fradelizi D, Wilson K, Triantafilou M (2002) GRP78, a coreceptor for coxsackievirus A9, interacts with major histocompatibility complex class I molecules which mediate virus internalization. J Virol 76: 633-643 
85. Ujino S, Yamaguchi S, Shimotohno K, Takaku H (2009) Heat-shock protein 90 is essential for stabilization of the hepatitis $\mathrm{C}$ virus nonstructural protein NS3. J Biol Chem 284: 6841-6846

86. Waxman L, Whitney M, Pollok BA, Kuo LC, Darke PL (2001) Host cell factor requirement for hepatitis C virus enzyme maturation. Proc Natl Acad Sci U S A 98: 13931-13935

87. Wright CM, Seguin SP, Fewell SW, Zhang H, Ishwad C, Vats A, Lingwood CA, Wipf P, Fanning E, Pipas JM, Brodsky JL (2009) Inhibition of Simian Virus 40 replication by targeting the molecular chaperone function and ATPase activity of $\mathrm{T}$ antigen. Virus Res 141: 71-80

88. Young P, Anderton E, Paschos K, White R, Allday MJ (2008) Epstein-Barr virus nuclear antigen (EBNA) 3A induces the expression of and interacts with a subset of chaperones and co-chaperones. J Gen Virol 89: 866-877

89. Zarate S, Cuadras MA, Espinosa R, Romero P, Juarez KO, Camacho-Nuez M, Arias CF, Lopez S (2003) Interaction of rotaviruses with Hsc70 during cell entry is mediated by VP5. J Virol 77: 7254-7260

90. Zhu XD, Li CL, Lang ZW, Gao GF, Tien P (2004) Significant correlation between expression level of HSP gp96 and progression of hepatitis B virus induced diseases. World J Gastroenterol 10: 1141-1145

91. Zuniga S, Sola I, Cruz JL, Enjuanes L (2009) Role of RNA chaperones in virus replication. Virus Res 139: 253-266 
Table 1. Virus-encoded chaperones which assist viral infection

\begin{tabular}{|c|c|c|c|c|}
\hline Virus & $\begin{array}{l}\text { Viral protein with } \\
\text { chaperone-like } \\
\text { activity }\end{array}$ & Function & $\begin{array}{l}\text { Effect on viral } \\
\text { infection }\end{array}$ & Reference \\
\hline \multirow[t]{2}{*}{ SV40 } & TAg & $\begin{array}{l}\text { Has J Domain of Hsp40 } \\
\text { required for host Hsp70 } \\
\text { recruitment }\end{array}$ & Viral assembly & Spence et al. 1994 [75] \\
\hline & & $\begin{array}{l}\text { Interaction with host } \\
\text { Hsc70 }\end{array}$ & Viral replication & Sullivan and Pipas 2002 [79] \\
\hline \multirow[t]{3}{*}{ HSV } & $\begin{array}{l}\text { Ribonucleotide } \\
\text { reductase S1 } \\
\text { subunit }\end{array}$ & $\begin{array}{l}\text { Hsp27-like chaperone } \\
\text { activity }\end{array}$ & Anti-apoptosis & Chabaud et al. 2003 [15] \\
\hline & ICP10PK & $\begin{array}{l}\text { Homologue to host } \\
\text { Hsp11 }\end{array}$ & $\begin{array}{l}\text { Modulation of virus- } \\
\text { induced apoptosis }\end{array}$ & Gober et al. 2005 [31] \\
\hline & NSP4 & $\begin{array}{l}\text { ER chaperone-like } \\
\text { activity }\end{array}$ & $\begin{array}{l}\text { Structural protein } \\
\text { VP4 folding }\end{array}$ & Suzuki 1996 [80] \\
\hline $\begin{array}{l}\text { African } \\
\text { swine fever } \\
\text { virus }\end{array}$ & $\begin{array}{l}\text { Capsid-associated } \\
\text { protein } 80\end{array}$ & Chaperone-like activity & $\begin{array}{l}\text { Capsid protein } \mathrm{p} 73 \\
\text { folding }\end{array}$ & Cobblod et al. 2001 [22] \\
\hline \multirow[t]{2}{*}{ HIV } & Tat & Nucleic acid chaperone & Viral DNA replication & Kuciak et al. 2008 [41] \\
\hline & $\begin{array}{l}\text { Nucleocapsid } \\
\text { protein }\end{array}$ & Nucleic acid chaperone & Viral DNA replication & $\begin{array}{l}\text { Thomas et al. } 2008 \text { [82]; } \\
\text { Ramalanjaona et al. } 2007 \text { [72] }\end{array}$ \\
\hline
\end{tabular}

SV40, simian virus 40; TAg, large tumor antigen; NSP4, non-structural protein 4; Tat, transcriptional activator; Hsp, heat shock protein; Hsc, heat shock cognate protein; VP4, viral protein 4; HSV, herpes simplex virus; HIV, human immunodeficiency virus ; ICP10PK, herpes simplex virus type 2 anti-apoptotic protein. 
Table 2. Therapeutic potentials by targeting molecular chaperones for the treatment of viral infection

\begin{tabular}{|c|c|c|c|c|}
\hline Virus & Treatment & Chaperone & Mechanism of action & Reference \\
\hline $\begin{array}{l}\text { Poliovirus, } \\
\text { Rhinovirus, } \\
\text { Coxsackievirus }\end{array}$ & $\begin{array}{l}\text { Geldanamycin } \\
\text { (Hsp90 inhibitor) }\end{array}$ & Hsp90 & $\begin{array}{l}\text { Disrupt viral capsid protein } \\
\text { folding/assembly }\end{array}$ & Geller et al. 2007 [30] \\
\hline Influenza virus & $\begin{array}{l}\text { Gelanamycin or its } \\
\text { derivative 17-AAG } \\
\text { (Hsp90 inhibitors) }\end{array}$ & Hsp90 & $\begin{array}{l}\text { Prevent nuclear import and } \\
\text { assembly of viral RNA } \\
\text { polymerase complex }\end{array}$ & Chase et al. 2008 [16] \\
\hline \multirow[t]{2}{*}{$\mathrm{HCV}$} & $\begin{array}{l}\text { 17-AAG } \\
\text { (Hsp90 inhibitor) }\end{array}$ & Hsp90 & $\begin{array}{l}\text { Destabilize HCV non- } \\
\text { structural protein NS3 }\end{array}$ & Ujino et al. 2009 [85] \\
\hline & $\begin{array}{l}\text { Cyclosporine A, } \\
\text { Debio 025, } \\
\text { NIM811, and SCY- } \\
635 \text { (Cyclophilin A } \\
\text { inhibitors) }\end{array}$ & Cyclophilin A & $\begin{array}{l}\text { Inhibit the chaperone } \\
\text { activity of cyclophilin A }\end{array}$ & Chatterji et al. 2009 [17] \\
\hline \multirow[t]{2}{*}{ HSV-1 } & $\begin{array}{l}\text { Geldanamycin } \\
\text { (Hsp90 inhibitor) }\end{array}$ & Hsp90 & $\begin{array}{l}\text { Promote aberrant folding, } \\
\text { mislocalization, and } \\
\text { degradation of viral } \\
\text { polymerase }\end{array}$ & $\begin{array}{l}\text { Burch et al. } 2005[13] \\
\text { Li et al. } 2004 \text { [47] }\end{array}$ \\
\hline & Hsp70 vaccine & Hsp70 & $\begin{array}{l}\text { Stimulate host innate and } \\
\text { adaptive immune responses }\end{array}$ & $\begin{array}{l}\text { Pack et al. } 2005 \text { [63]; } \\
\text { Pack et al. } 2008 \text { [64] }\end{array}$ \\
\hline \multirow[t]{2}{*}{ HBV } & $\begin{array}{l}\text { 17-AAG } \\
\text { (Hsp90 inhibitor) }\end{array}$ & $\begin{array}{l}\text { Hsp90/Hsp70/ } \\
\text { Hsp60 }\end{array}$ & $\begin{array}{l}\text { Disrupt the interaction of } \\
\text { Hsp90 with Hsp70/Hsp60 }\end{array}$ & Liu et al. 2009 [51] \\
\hline & Hsp70 vaccine & Hsp70 & $\begin{array}{l}\text { Elicit host immune } \\
\text { responses }\end{array}$ & Peng et al. 2006 [67] \\
\hline Cytomegalovirus & $\begin{array}{l}\text { Geldanamycin } \\
\text { (Hsp90 inhibitor) }\end{array}$ & Hsp90 & Disrupt PI3K/Akt pathway & Basha et al. 2005 [7] \\
\hline Epstein-Barr virus & $\begin{array}{l}\text { Gelanamycin or its } \\
\text { derivative 17-AAG } \\
\text { (Hsp90 inhibitors) }\end{array}$ & Hsp90 & Disrupt PI3K/Akt pathway & Jeon et al. 2007 [36] \\
\hline \multirow[t]{2}{*}{ HIV } & $\begin{array}{l}\text { Small molecular } \\
\text { compounds }\end{array}$ & Cyclophilin A & $\begin{array}{l}\text { Inhibit the chaperone } \\
\text { activity of cyclophilin A }\end{array}$ & Chen et al. 2007 [18] \\
\hline & Hsp70 vaccine & Hsp70 & $\begin{array}{l}\text { Elicit host immunity against } \\
\text { HIV }\end{array}$ & $\begin{array}{l}\text { Babaahmady et al. } 2007 \text { [5]; } \\
\text { Babaahmady et al. } 2008 \text { [6] }\end{array}$ \\
\hline SV40 & $\begin{array}{l}\text { Small molecular } \\
\text { compound }\end{array}$ & TAg & $\begin{array}{l}\text { Inhibit TAg's chaperone } \\
\text { activity }\end{array}$ & Wright et al. 2009 [87] \\
\hline SIV & Hsp70 vaccine & Hsp70 & $\begin{array}{l}\text { Elicit host innate and } \\
\text { adaptive immunity }\end{array}$ & Lehner et al. 2000 [45] \\
\hline
\end{tabular}


17-AAG, 17-allylamino-17-demethoxygeldanamycin ; Hsp, heat shock protein; HCV, hepatitis C virus ; NS3, non-structural protein 3 ; HBV, hepatitis B virus ; PI3K, phosphatidylinositol 3kinase; HSV, herpes simplex virus; HIV, human immunodeficiency virus ; SV40, simian virus 40 ; TAg, large tumor antigen; SIV, simian immunodeficiency virus. 


\section{Figure legends}

Figure 1. Schematic illustration of the functions of molecular chaperones. Molecular chaperones assist folding and assembly of newly synthesized polypeptides to the native proteins. Chaperones also bind to misfolded proteins induced by stress to help correct folding and assembly. Terminally-misfolded or unfolded proteins are escorted by chaperones for degradation through the ubiquitin-proteasome system.

Figure 2. Interplay between viruses and host chaperones. Virus infection can lead to increased production of host chaperones either as a direct effect of virus infection or an indirect response to cellular stress induced by infection. Through different mechanisms, both direct and indirect, chaperones can have diverse pro-viral or anti-viral roles during various stages of the viral life cycle including cell entry, nuclear import, viral genome replication, and the folding/assembly of viral proteins. In addition, chaperones can have a significant effect on viral pathogenesis due to their involvement in the regulation of host immunity and apoptosis. Hsc70, heat shock cognate protein 70; Hsp: heat shock protein; GRP, glucose-regulated protein; HCV, hepatitis C virus; HBV, hepatitis B virus; HIV, human immunodeficiency virus. 


\section{Figure 1.}

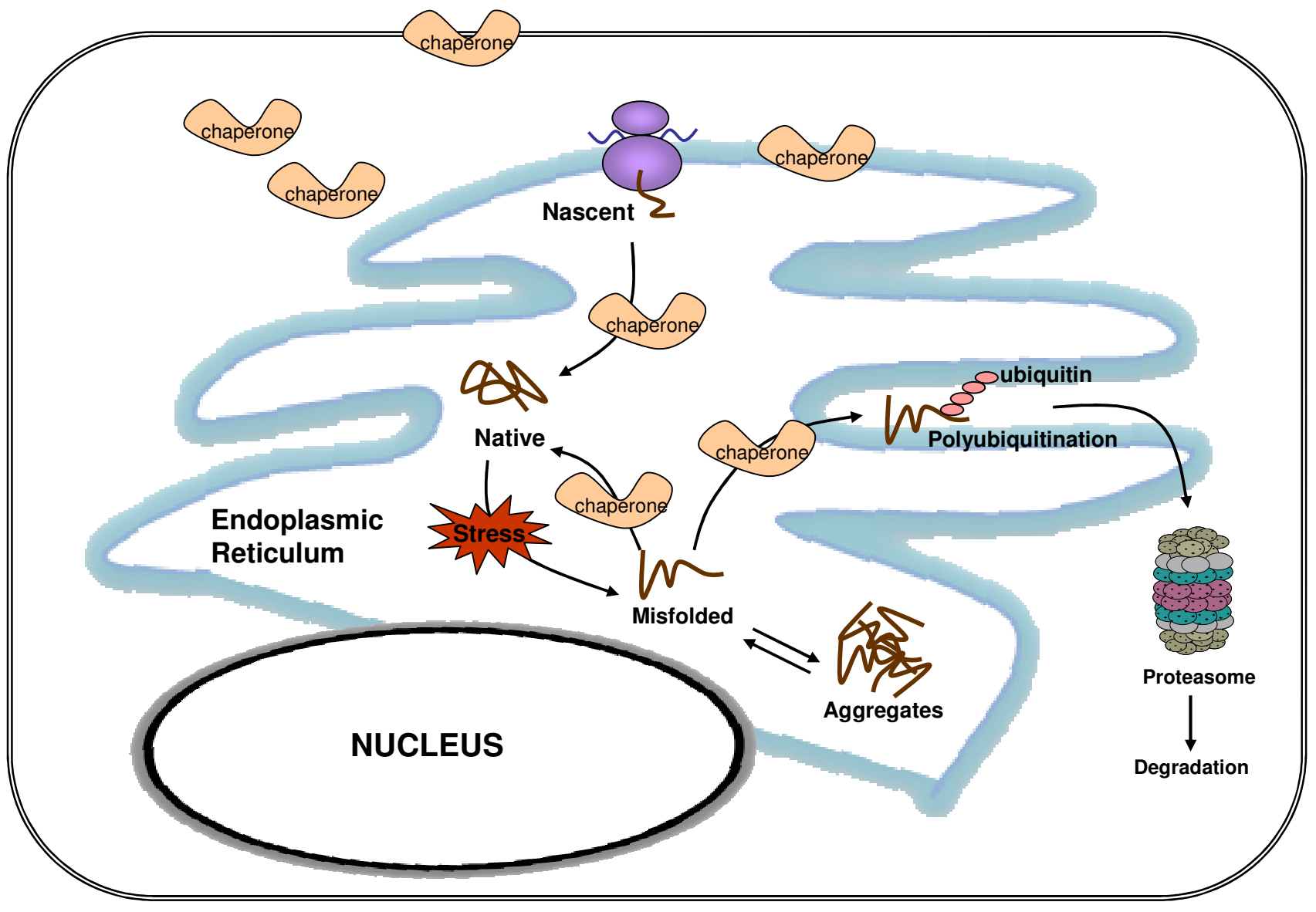


Figure 2.

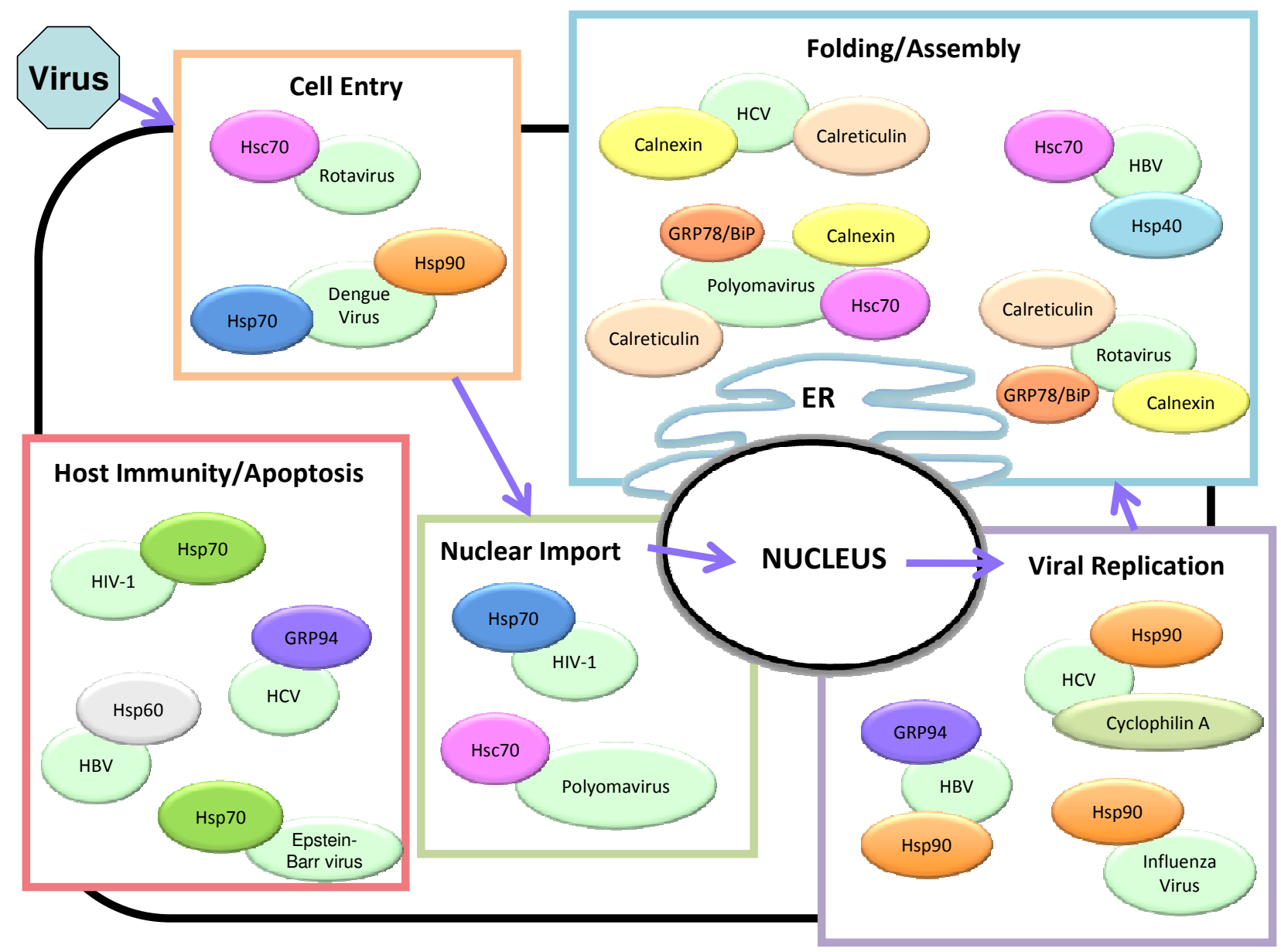

